\title{
Motor function of the proximal stomach and visceral perception in gastro-oesophageal reflux disease
}

\author{
R Penagini, G Hebbard, M Horowitz, J Dent, H Bermingham, K Jones, R H Holloway
}

\begin{abstract}
Background-The abnormally high postprandial rate of transient lower oesophageal sphincter relaxations seen in patients with reflux disease may be related to altered proximal gastric motor function. Heightened visceral sensitivity may also contribute to reporting of symptoms in these patients.
\end{abstract}

Aims-To assess motor function of the proximal stomach and visceral perception in reflux disease with a barostat.

Methods-Fasting and postprandial proximal gastric motility, sensation, and symptoms were measured in nine patients with reflux disease and nine healthy subjects. Gastric emptying of solids and liquids was assessed in six of the patients on a different day (and compared to historical controls).

Results-Minimal distending pressure and gastric compliance were similar in the two groups, whereas the patients experienced fullness at lower pressures $(p<0.05)$ and discomfort at lower balloon volumes $(p<0.005)$ during isobaric and isovolumetric distensions respectively. Maximal gastric relaxation induced by the meal was similar in the two groups. Late after the meal, however, proximal gastric tone was lower $(p<0.01)$ and the score for fullness higher $(p<0.01)$ in the reflux patients, in whom the retention of both solids and liquids in the proximal stomach was greater $(\mathbf{p}<0.05)$.

Conclusions-Reflux disease is associated with delayed recovery of proximal gastric tone after a meal and increased visceral sensitivity. The former may contribute to the increased prevalence of reflux during transient lower oesophageal sphincter relaxations and the delay in emptying from the proximal stomach, whereas both may contribute to symptom reporting.

(Gut 1998;42:251-257)

Keywords: barostat; tone; compliance; mechanics

Gastro-oesophageal reflux disease is caused primarily by excessive exposure of the oesophagus to gastric contents that, in most cases, is due to an abnormally high rate of reflux episodes. ${ }^{1}$ It is now established that reduced lower oesophageal sphincter (LOS) pressure is not the major mechanism responsible for reflux and that the majority of reflux episodes occur during transient LOS relaxations. ${ }^{1-3}$ Further- more, recent evidence suggests that enhanced visceral perception may contribute to the level of symptoms reported in reflux disease. ${ }^{4}$

It is recognised that gastric distension, particularly of the proximal stomach, is a major stimulus for transient LOS relaxations. ${ }^{5-7}$ It is now also clear that gastric emptying is delayed in about $40 \%$ of patients with reflux disease..$^{8-10}$ Despite the importance of the proximal stomach in the pathogenesis of reflux disease, information about proximal gastric function in reflux disease is limited. ${ }^{11}$ Although antral motility has been reported to be reduced in reflux oesophagitis ${ }^{12}$ the motor function of the proximal stomach has not been studied.

Patients with reflux disease commonly complain of dyspeptic symptoms-upper abdominal discomfort or pain which is distinct from heartburn. ${ }^{13-15}$ These symptoms could reflect increased visceral sensitivity of the upper gut as has been well documented in non-ulcer dyspepsia, ${ }^{16}{ }^{17}$ or disordered motility causing excessive proximal gastric distension after meals. ${ }^{18}$

This study was designed to evaluate the previously unstudied aspects of the motor function of the proximal stomach and visceral perception in patients with reflux disease in both the fasted and postprandial state.

\section{Methods}

PATIENTS

Nine patients (eight males and one female, aged 21-55 years), with erosive or ulcerative oesophagitis that had been documented endoscopically within one month of the study were studied. They had a body mass index (BMI) ranging from 22 to 36 (mean 30). Patients were excluded if they had a large (greater than $5 \mathrm{~cm}$ ) hiatus hernia, diseases other than reflux disease known to affect oesophageal motility (for example, scleroderma), previous peptic ulceration, or had undergone gastric surgery. Nine age matched healthy volunteers (seven males and two females, aged 21-54 years) served as controls. They had a BMI ranging from 19 to 36 (mean 25) and were free of gastrointestinal symptoms. There was no significant difference in age or BMI between the two groups. All subjects gave written informed consent and the study was approved by the Research Ethics Committee of the Royal Adelaide Hospital.

BAROSTAT MEASUREMENTS

Proximal gastric function was measured with an electronic barostat (model JS10987, Janssen Scientific Instruments, Janssen Pharmaceutica, 
Belgium).${ }^{19}$ The barostat had a maximum displacement of approximately $800 \mathrm{ml}$ and maintained a constant pressure or volume in a polyethylene bag which had a capacity of approximately $1100 \mathrm{ml}$. A bellows mechanism introduced or withdrew air from the bag at 30 $\mathrm{ml}$ per second via a tube of $2.5 \mathrm{~mm}$ internal diameter (ID) and $650 \mathrm{~mm}$ length when the pressure measured in the bag differed from the set pressure by more than $0.4 \mathrm{~mm} \mathrm{Hg}$. Pressure in the barostat bag was sensed via a $0.97 \mathrm{~mm}$ ID tube which was incorporated into the barostat inflation assembly. Approximately $10 \mathrm{~cm}$ of tubing was present below the bag to aid insertion through the pharynx. A further two manometric lumina also incorporated into the assembly had sideholes positioned 25 and 50 $\mathrm{mm}$ proximal to the top of the barostat bag which allowed reliable positioning of the bag within the stomach by detection of the characteristic patterns of pressure at the level of the diaphragm. These lumina were perfused with degassed distilled water using a pneumohydraulic perfusion pump. Pressures were sensed by external transducers connected to a multichannel recording system (Synectics Medical, Sweden).

Data from the barostat and pressure recording system were digitised at $10 \mathrm{~Hz}$ using a National Instruments NBMIO16H analogue to digital conversion board (National Instruments Corporation, Austin, Texas) in a Macintosh IIci computer (Apple Computer Inc., Cupertino, California). The digitised signals were displayed and stored with software (MAD, Prof C-H Malbert, INRA, Rennes, France) based on Labview (National Instruments Corporation, Texas).

\section{MEASUREMENT OF GASTRIC EMPTYING}

Gastric emptying of solids and liquids was measured with a dual isotope method. ${ }^{20}$ The solid component of the meal was $100 \mathrm{~g}$ of cooked ground beef containing $20 \mathrm{MBq}$ of chicken liver labelled in vivo with technetium$99 \mathrm{~m}$ labelled sulphur colloid. The liquid component was $150 \mathrm{ml}$ of $10 \%$ dextrose in water labelled with $7 \mathrm{MBq}$ of indium-113m labelled diethylenetriamenepenta-acetic acid.

\section{ASSESSMENT OF SYMPTOMS}

The pressure and volume at which the subject first experienced fullness, discomfort, and pain were recorded during pressure controlled (isobaric) and volume controlled (isovolumetric) distensions respectively. Immediately before and after consumption of a meal, subjective ratings of hunger and fullness were assessed at 15 minute intervals with a validated $100 \mathrm{~mm}$ visual analogue scale. ${ }^{21}$

ASSESSMENT OF AUTONOMIC NERVE FUNCTION Autonomic nerve function was assessed by the standardised measurement of cardiovascular reflexes. ${ }^{1022}$

PROTOCOL

Barostat study

The study was performed in all patients and volunteers after they had fasted overnight and had undergone assessment of autonomic nerve function. The barostat assembly, with the bag folded around it, was introduced via an anaesthetised nostril and positioned well into the stomach on the basis of the manometric recording. The bag was then unfolded by inflation with $500 \mathrm{ml}$ of air, while ensuring that the pressure in the bag did not exceed $20 \mathrm{~mm} \mathrm{Hg}$. The bag was then deflated and the position of the assembly adjusted to its final position so that the point of respiratory reversal lay between the manometric sideholes, thereby positioning the proximal portion of the bag just below the diaphragm. The assembly was then fixed in this position by taping it to the nose. Subjects sat upright on a comfortable stool in a standardised position so as not to compress the abdomen. After approximately 15 minutes to allow the subject to accommodate to the assembly, minimal distending pressure (MDP), defined as the intrabag pressure at which continuous respiratory fluctuations in pressure (greater than $1 \mathrm{~mm} \mathrm{Hg}$ ) and volume (greater than $30 \mathrm{ml}$ ) were first detected, was determined during stepwise inflation of the bag in $1 \mathrm{~mm} \mathrm{Hg}$ increments of 30 seconds each.

Isobaric (pressure controlled) and isovolumetric (volume controlled) distensions, separated by a 10 minute interval, were then performed in randomised order. Before each series of distensions, the barostat was set to maintain an intrabag pressure $2 \mathrm{~mm} \mathrm{Hg}$ above MDP for five minutes in order to ensure that no rhythmic volume waves ${ }^{23}$ were present. If such waves were present, they were monitored and the distension done only when they had stopped. During the isobaric distensions, gastric balloon pressure was increased in $1 \mathrm{~mm}$ $\mathrm{Hg}$ steps starting $2 \mathrm{~mm} \mathrm{Hg}$ below the previously determined MDP to either a pressure of $12 \mathrm{~mm} \mathrm{Hg}$ above MDP, the threshold of pain, or the maximum volume of the barostat $(800 \mathrm{ml})$. Measurements were made for two minutes at each pressure step. During the isovolumetric distensions the bag was inflated in $100 \mathrm{ml}$ increments with each step being maintained for two minutes, to either $800 \mathrm{ml}$, or the threshold for pain. Symptoms were assessed as described above.

After the distensions, the balloon was deflated completely and the subjects allowed to move about for 10 minutes. The barostat was then set again at $2 \mathrm{~mm} \mathrm{Hg}$ above MDP and fasting recordings performed for 20 minutes. If rhythmic volume waves were detected, the start of the fasting recording was postponed until they had stopped. The subjects were then fed a soft meal consisting of savoury mince, mashed vegetables, ice cream, and milk (3.150 MJ, $36 \mathrm{~g}$ (43\%) fat) which was consumed with the bag deflated. The bag was then reinflated to $2 \mathrm{~mm}$ $\mathrm{Hg}$ above MDP and recordings made for two hours. Symptoms of hunger and fullness were assessed at 15 minute intervals as described above.

Gastric emptying study

Gastric emptying was measured on a separate day, one to four weeks after the barostat study, but this assessment could be done in only six of 
the nine patients because the remainder were unwilling to undergo the test. The study was performed at approximately 13.00 when the subject had fasted after a light breakfast at 07.00. Each patient sat with his or her back to the scintillation camera, ate the solid meal over a five minute period, and then immediately drank the dextrose solution. Time zero was defined as the time of meal completion and each study was continued for at least two hours. $^{20}$

DATA ANALYSIS

Data from the barostat were imported into a display and analysis program (Acqknowledge, Biopac Systems, Goleta, California). During the isobaric and isovolumetric distensions, mean values for intrabag volume and pressure, respectively, were determined for the second minute of each distension step and the values at which fullness, discomfort, or pain were first perceived were recorded. Values for volumes were corrected for the internal compliance of the barostat unit and the effects of air compression using an experimentally measured constant $(6.5 \mathrm{ml} / \mathrm{mm} \mathrm{Hg})$. Values for pressure were expressed as $\mathrm{mm} \mathrm{Hg}$ above MDP.

For the fasting and postprandial recordings, mean barostat volume was determined at five minute intervals by counting the mean intrabag volume over that period. Variations attributable to volume waves were excluded. ${ }^{23}$ Fasting tone was calculated as the mean intrabag volume over the 20 minute observation period. Postprandial relaxation was determined as the increase in intrabag volume above mean fasting volume and calculated over 15 minute intervals from the five minute values. Maximum postprandial relaxation was defined as the maximal and uniform (variations less than $30 \mathrm{ml}$ ) increase in intrabag volume observed after the meal. ${ }^{24}$

Gastric emptying data were corrected for patient movement, radionuclide decay, and Compton scatter. Correction for radionuclide gamma ray attenuation was done using factors derived from a lateral image of the stomach. ${ }^{20}$ The lag phase before any of the solid component of the meal entered the duodenum, the amount of the solid component remaining in the stomach at 100 minutes after the meal, and the time for $50 \%$ emptying of the liquid component were calculated. The total stomach region of interest was also divided into proximal and distal regions, with the proximal region corresponding to the fundus and proximal corpus, and the distal region representing the distal corpus and antrum. ${ }^{25}$ For the proximal and distal stomach, the amount of the solid meal remaining at 100 minutes and the amount of liquid remaining at 30 minutes were derived. Gastric emptying data were compared with an established normal range derived from 20 controls aged 18 to 63 years (mean 37 years) with a BMI between 18 and 27 (mean 23). ${ }^{10} 20$ Gastric emptying and intragastric distribution were judged to be abnormal when values were outside the mean (2SD) for this group.
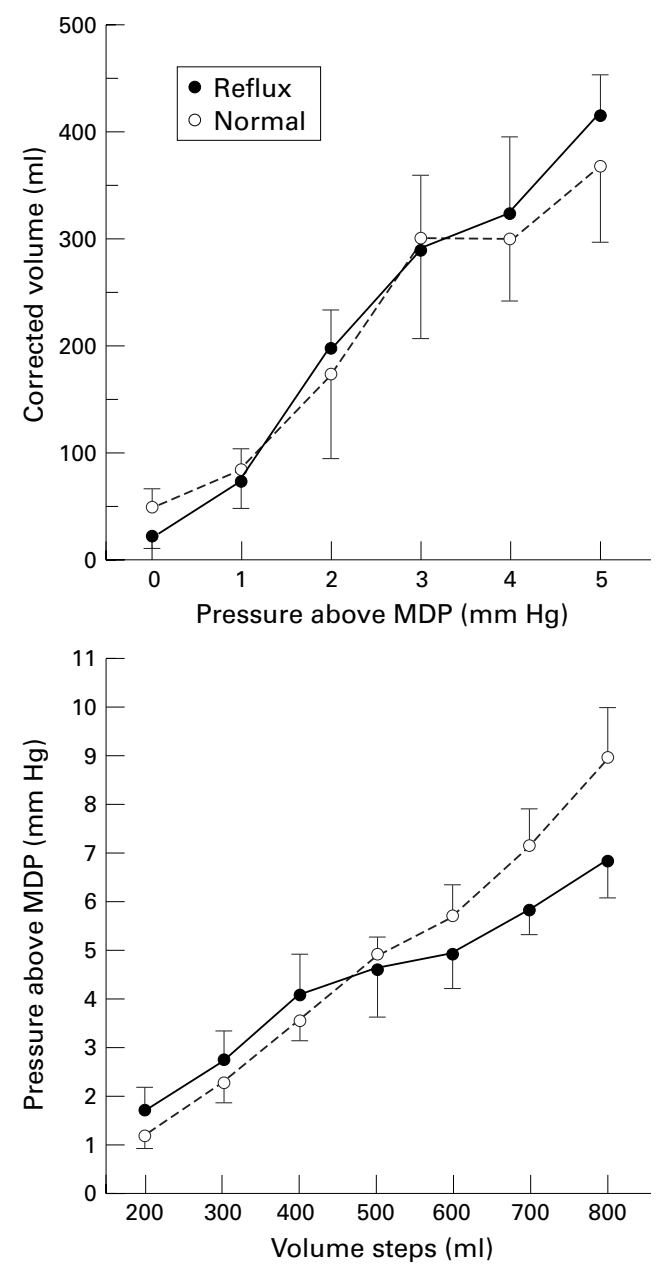

Figure 1 Relation between intragastric pressure and volume during fasting isobaric (upper panel) and isovolumetric (lower panel) distension of the stomach.

STATISTICAL ANALYSIS

Statistical significance of differences in intragastric volume and pressure and in perception between patients and healthy volunteers was assessed by Student's unpaired $t$ test for the fasting data and by repeated measures analysis of variance after the meal. These data are given as mean (SEM). Gastric emptying data were analysed with the Mann-Whitney $U$ test and are expressed as median (interquartile range, IQR). The relation between intragastric volume and scores for fullness and hunger were evaluated by linear regression analysis. A p value of less than 0.05 was accepted as indicating statistical significance.

\section{Results}

FASTING RECORDINGS

None of the patients or controls had abnormal autonomic nerve function. Minimal distending pressure and fasting intrabag volume were similar in the patients with reflux disease and in the controls $(6.6(0.6) \mathrm{mm} \mathrm{Hg}$ versus 6.0 (0.4) $\mathrm{mm} \mathrm{Hg}$ and 158 (19) $\mathrm{ml}$ versus 176 (37) $\mathrm{ml}$ ). The pressure volume curves were also similar in the two groups for both isobaric and isovolumetric distensions (fig 1), indicating that fasting compliance was also similar.

There was a trend for the score for fullness when fasting to be higher in the patients, 


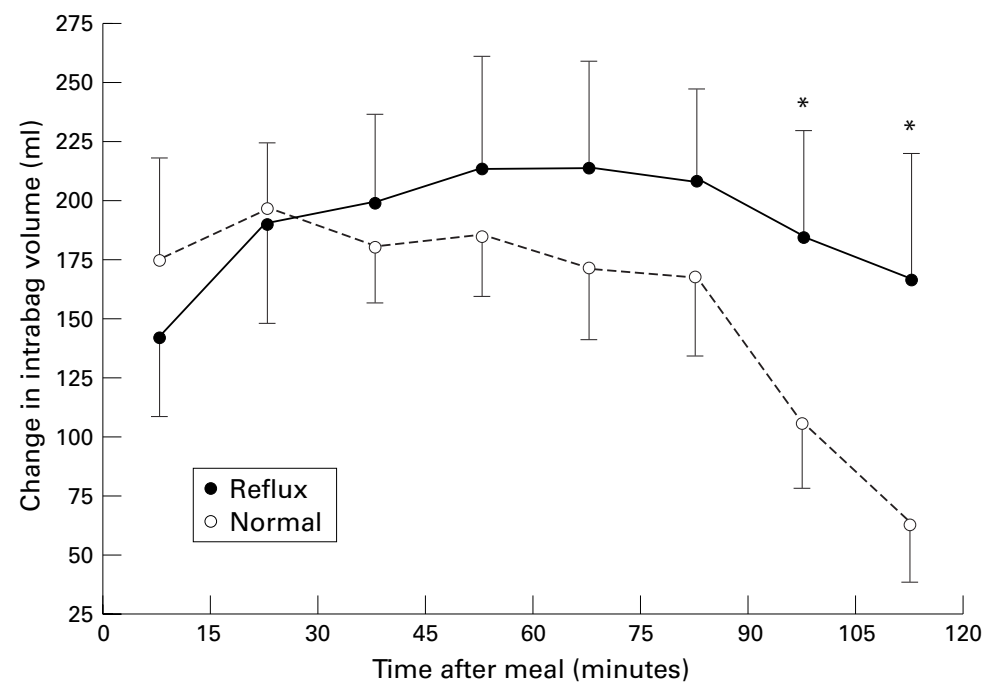

Figure 2 Postprandial change in proximal gastric volume. Data are expressed as mean (SEM); ${ }^{\star} p<0.01$ versus normal.
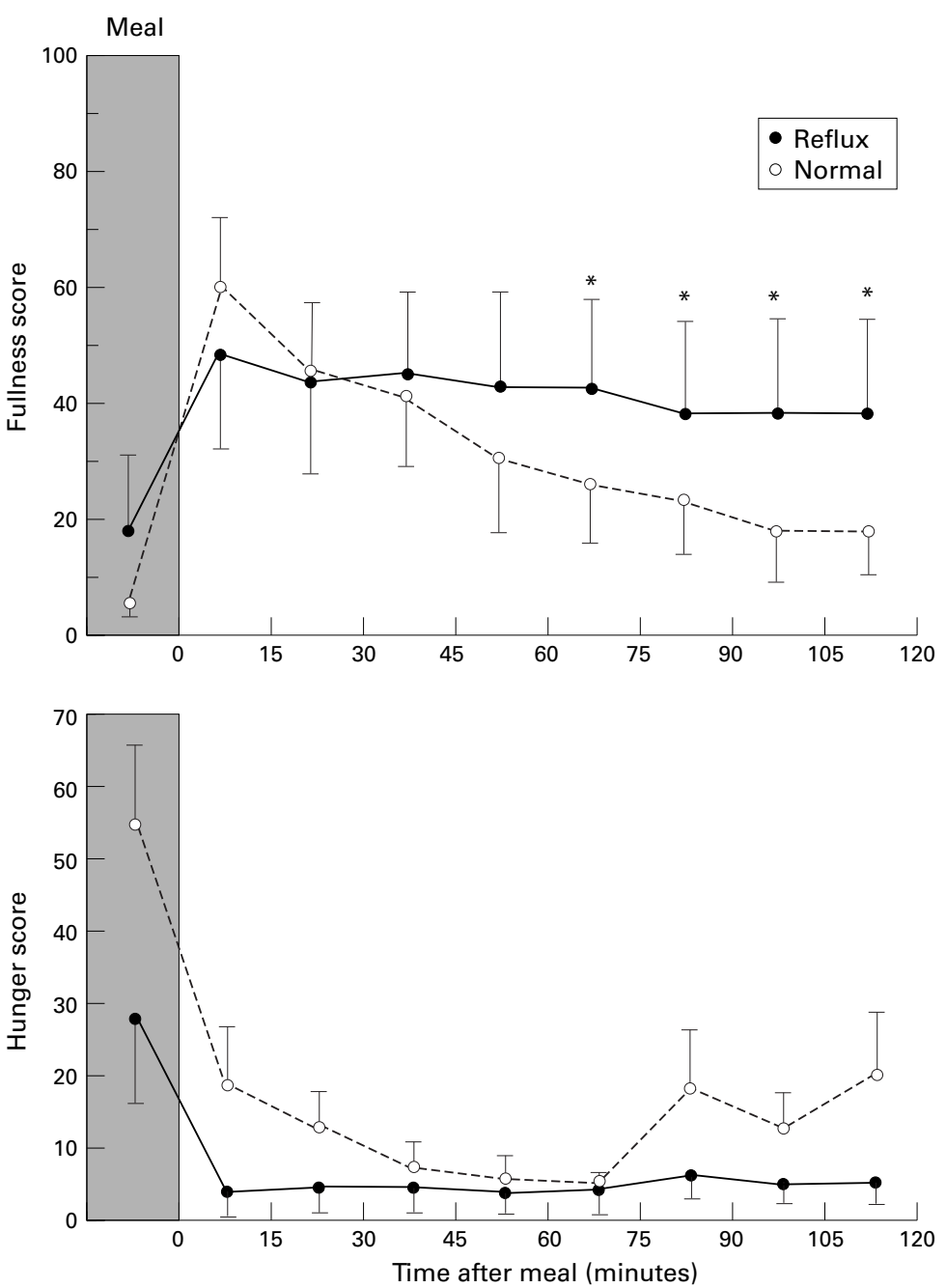

Figure 3 Scores for fullness (upper panel) and hunger (lower panel) before and after a meal. Data are expressed as mean $(S E M) ;{ }^{\star} p<0.01$ versus normal.

although there was high variability (18 (13) $\mathrm{mm}$ versus 6 (2) $\mathrm{mm}$, NS). Fasting hunger scores were lower in the patients $(28$ (12) $\mathrm{mm}$ versus 55 (11) $\mathrm{mm}, \mathrm{p}<0.01)$. During the isobaric distension the patients experienced fullness at a lower pressure than did the normals (3.1 (0.4) $\mathrm{mm} \mathrm{Hg}$ versus $5.0(0.8) \mathrm{mm}$ $\mathrm{Hg}$ above MDP, $\mathrm{p}<0.05)$. A similar trend was present for discomfort (4.6 (0.5) $\mathrm{mm} \mathrm{Hg}$ versus $6.7(2.1) \mathrm{mm} \mathrm{Hg})$, but too few $(\mathrm{n}=3)$ healthy subjects experienced the symptom to permit statistical comparison with the patients $(n=5)$. During the isovolumetric distension, the patients experienced discomfort at lower volumes than did the normal subjects (339 (43) $\mathrm{ml}$ versus 585 (36) $\mathrm{ml}, \mathrm{p}<0.005)$. Patients also experienced fullness at a lower volume although this difference was not statistically different (324 (65) ml versus 417 (47) $\mathrm{ml}$, NS). Overall, six patients experienced fullness or discomfort at a pressure (in the isobaric distensions) or a volume (in the isovolumetric distensions) below the control range seen in this study.

\section{POSTPRANDIAL RECORDINGS}

After the meal, patients with reflux disease and controls had similar maximal relaxation volumes of the proximal stomach $(295$ (53) $\mathrm{ml}$ versus 308 (25) $\mathrm{ml}$ ). Intragastric volume remained significantly higher than during fasting for the subsequent two hours in both groups. In the controls there was a partial recovery of proximal gastric tone after $90 \mathrm{~min}-$ utes. In contrast, in patients with reflux disease, there was almost no recovery of tone during the whole observation period, so that tone was lower $(\mathrm{p}<0.01)$ than in the controls after 90 minutes (fig 2). In three of the patients values for tone after 90 minutes were below the control range for this study.

After consumption of the meal, fullness scores increased in both groups and the values were higher than fasting values $(p<0.05)$ up to 75 minutes in the controls and at all time points in the patients. Hunger scores decreased significantly $(\mathrm{p}<0.05$ when compared with fasting) throughout the postprandial period in both groups. Although mean sensation scores for fullness paralleled the changes in intragastric volume, there was no statistically significant relationship between fullness and intrabag volume $(r=0.1, \mathrm{NS})$. In contrast, there was a significant inverse relationship between hunger and intrabag volume $(r=0.04, p<0.01)$. In patients with reflux disease, the scores for fullness were higher than in the control subjects from 75 minutes after the meal was completed $(p<0.01$, fig 3). None of the controls or patients reported nausea after the meal.

\section{GASTRIC EMPTYING}

The duration of the lag phase for the solid component of the meal (reflux 34 minutes, IQR 26 to 38 minutes; control 26 minutes, IQR 21 to 35 minutes) was similar in the two groups. There was no significant difference in the retention of solids in the total stomach at 100 minutes in the reflux patients $(58 \%$, IQR 31 to $69 \%$ ) when compared with that in the controls $(44 \%$, IQR 34 to $55 \%)(p=0.1)$; however, in three patients values were above the control range (fig 4). Gastric emptying of the liquid component of the meal from the total stomach was similar in the two groups (fig 4). 


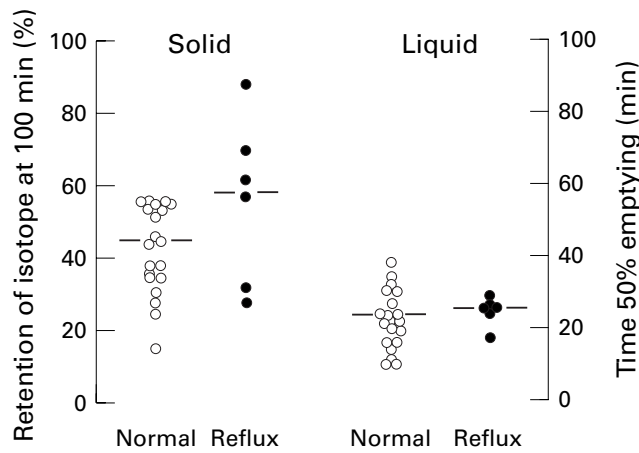

Figure 4 Emptying of the solid and liquid component from the total stomach. Each point represents the value for a single subject. The horizontal bars indicate median values.
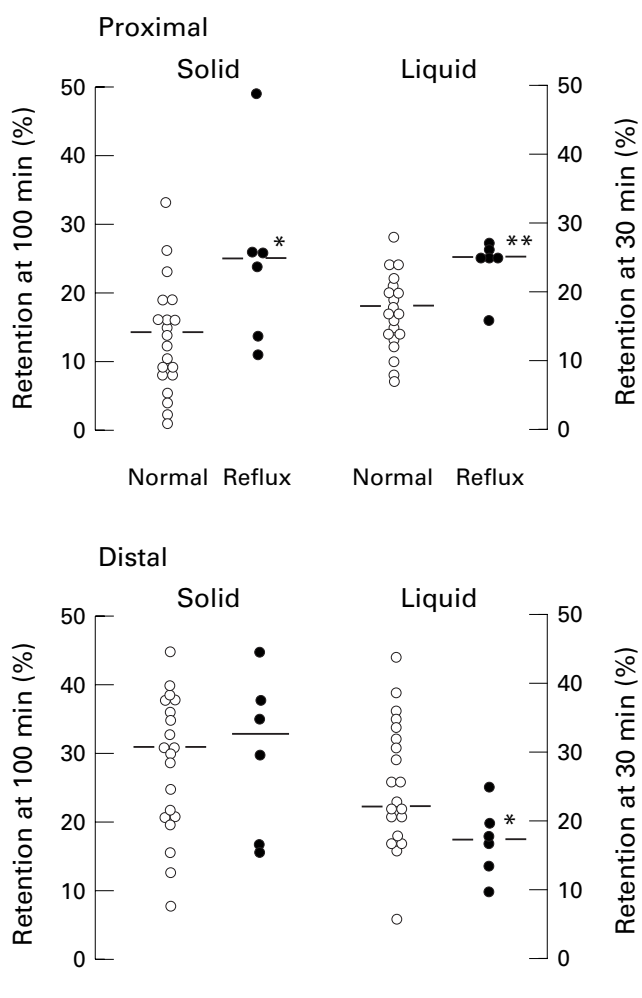

Figure 5 Emptying of the solid and liquid components of a meal from the proximal (upper panel) and distal (lower panel) stomach. Each point represents the value for a single subject. The horizontal bars indicate median values. ${ }^{\star} p<0.05$ versus normal, ${ }^{\star *} p<0.01$ versus normal.

The retention of both solids and liquids in the proximal stomach was greater in the patients than in the controls (solids $25 \%$ (IQR 14 to $26 \%$ ) versus $14 \%$ (IQR 9 to $18 \%$ ), p $<0.05$; and liquids $25 \%$ (IQR 25 to $26 \%$ ) versus $18 \%$ (IQR 14 to $21 \%$ ), p<0.01; fig 5 ), and in one of the patients the retention of the solid meal in the proximal stomach was above the control range.

The retention of solids in the distal stomach was similar in the two groups whereas retention of liquids was marginally less in the patients (17\%, IQR 14 to $20 \%$ ) than in the controls $(22 \%$, IQR 17 to $31 \%)(\mathrm{p}<0.05)$.

\section{Discussion}

This is the first barostat study of proximal gastric function in patients with reflux disease in both the fasting and postprandial states. We have shown that in patients with reflux disease: (1) fasting compliance and postprandial relaxation of the proximal stomach are similar to those in normal subjects while postprandial recovery of tone is delayed; (2) visceral sensitivity is increased, as indicated by a reduction in the threshold for perception of fullness and of discomfort during gastric distension; and (3) emptying of solids and liquids from the proximal stomach is delayed.

The major difference that we found between patients with reflux disease and controls was that the recovery of tone after food was delayed significantly in patients with reflux disease. This delay is consistent with, and provides an explanation for, the slower emptying of both solids and liquids from the proximal stomach. The mechanism(s) underlying the delayed recovery of tone are unclear. It could be a consequence of delayed gastric emptying from the whole stomach and/or increased inhibitory feedback from small intestinal nutrient receptors. ${ }^{2627}$ It could also be potentially related to abnormal cholinergic vagal tone.$^{28}$ In dogs, fasting proximal gastric tone is maintained largely by vagal cholinergic input, ${ }^{29}$ and vagal function has been shown to be impaired in some patients with reflux oesophagitis. ${ }^{30}$ Furthermore, truncal vagotomy prolongs the recovery of proximal gastric tone following insulin induced proximal gastric relaxation. ${ }^{31}$ However, fasting proximal gastric tone was not lower in our patients and postprandial relaxation was not impaired as would be expected in the presence of vagal damage..$^{32-34}$

Our finding that fasting gastric compliance in patients with reflux disease did not differ from that in controls during both isobaric and isovolumetric distension is at variance with that of an earlier study which reported that the increase in intragastric pressure with gastric distension was less in patients with reflux disease than in normal subjects. ${ }^{11}$ The disparity appears to arise largely from differences in the control responses between the two studies. We recorded similar mean gastric pressures (approximately $10 \mathrm{~mm} \mathrm{Hg}$ at a volume of $400 \mathrm{ml}$ ) in the patients with reflux disease to those in the earlier study. In contrast, we found lower pressures in the normal subjects to those of the earlier study. This difference might reflect different methodological approaches. Firstly, the patients and the controls in the previous study were not well age matched. Secondly, the previous study assessed compliance during relatively rapid continuous ramp isovolumetric distension and at one static volume, compared with our approach of stepwise inflation at several volumes. We have found that continuous ramp distension yields less reproducible results than the stepwise methods (Hebbard, unpublished observations) and rapid distension records lower values for compliance than does slow distension. ${ }^{35}$ Thirdly, posture has a significant effect on measurement of gastric compliance in a manner that suggests that extragastric compression may be a major influence on gastric distension pressure. ${ }^{19}$ Although our subjects as well as those in the previous study were studied sitting, it is possible that 
there were minor but nevertheless important differences in posture between the two studies that might have influenced the results.

The other major finding of our study was evidence for increased visceral sensitivity in the patients with reflux disease. During isobaric distension, a lower threshold was noted for the sensation of fullness and, during isovolumetric distension, the threshold for discomfort was lower. The lack of any differences in the sensation of fullness during isovolumetric distension and of discomfort during isobaric distension may have been a result of a type 2 error due to the relatively small sample size. Nevertheless, in six of the nine patients either the threshold for fullness or discomfort was below the range of control values. We did not quantify the intensity of sensations during the distensions, which may have been of value. Our observations are similar to those in patients with functional dyspepsia, ${ }^{17}$ and are consistent with previous studies of oesophageal distension in patients with reflux disease. $^{36}$ Patients with reflux disease often report epigastric pain, bloating, and nausea, ${ }^{14}{ }^{15}$ and increased gastric sensitivity may contribute to the perception of dyspeptic symptoms in patients with reflux disease despite similar gastric compliance to that in normal subjects. As the pressure volume relationship of the proximal stomach was similar in the patients and controls, the increased sensation in the patients cannot be attributed to abnormal compliance of the proximal stomach.

We found a significant relationship between postprandial hunger and proximal gastric volume, and the increased fullness in the late postprandial period paralleled the time course of the difference in postprandial gastric volume. It is not possible to be certain whether these findings relate to an increased sensitivity, or to the greater intragastric volume. However, it appears more probable that more prolonged postprandial gastric distension contributes to the increased reporting of dyspeptic symptoms by patients with reflux disease. The regulation of appetite is a complex process involving a variety of central and peripheral mechanisms. ${ }^{37}$ Our data support previous observations suggesting that gastric distension is one of the stimuli that decrease hunger. ${ }^{38}{ }^{39}$ Although we did not find a relation between recovery of tone and proximal gastric emptying, the number of patients studied was small, the two measurements were done on separate days, and gastric tone is only one of the factors responsible for emptying from the proximal stomach; others include posture, meal composition, and small intestinal feedback. ${ }^{39}$ Slow gastric emptying from the stomach as a whole is seen in about $50 \%$ of patients with reflux disease. ${ }^{910}$ While we did not detect a significant difference in gastric emptying from the total stomach, the observation that gastric emptying of solids was outside the control range in three of six patients is consistent with previous studies.

The significance of our findings to the pathogenesis of reflux disease remains speculative at this stage and awaits further study. However, some inferences can be drawn. Gastric distension, particularly of the proximal stomach, ${ }^{7}$ is the major factor that triggers transient LOS relaxations, ${ }^{40}$ and reflux patients have a higher postprandial rate of these events. ${ }^{41}$ As the mechanoreceptors believed to be responsible for mediating the gastric distension induced increase in transient LOS relaxations appear to be tension rather than stretch receptors, ${ }^{42}$ we had anticipated that patients with reflux disease might exhibit greater gastric wall tension during either distension or postprandially to account for the higher rate of transient LOS relaxations. If current ideas about the behaviour of gastric mechanoreceptors are correct, the finding of similar fasting compliance and postprandial relaxation in patients with reflux disease to that in controls suggests that the increased rate of transient LOS relaxations soon after meals results from abnormalities elsewhere in the neural pathway that mediates these events. However, the persistence of a larger proximal gastric volume in the late postprandial period may underlie the tendency for reflux episodes to continue for longer periods after the meal, and may also be an important determinant of the higher percentage of transient LOS relaxations associated with reflux in patients with reflux disease. $^{34344}$

In summary, we have found significant impairment of proximal gastric motor function and increased sensitivity in patients with reflux disease. The first abnormality may explain, at least in part, the delayed gastric emptying and a higher association of transient LOS relaxations with reflux, whereas both abnormalities may contribute to a greater level of perception of symptoms.

This study was supported by a grant from the National Health and Medical Research Council of Australia. The authors are grateful to Dr B Chatterton for allowing the gastric emptying studies to be performed in the Department of Nuclear Medicine.

1 Dodds WJ, Dent J, Hogan WJ, et al. Mechanisms of gastroesophageal reflux in patients with reflux esophagitis. $N \mathrm{Engl}$ fMed 1982;307:1547-52.

2 Dent J, Holloway RH, Toouli J, Dodds WJ. Mechanisms of lower oesophageal sphincter incompetence in patients with symptomatic gastro-oesophageal reflux Gut 1988;29: 1020-8

3 Penagini R, Schoeman MN, Dent J, Tippett MD, Holloway $\mathrm{RH}$. Motor events underlying gastro-oesophageal reflux in ambulant patients with reflux oesophagitis. Fournal of $\mathrm{Neu}$ rogastroenterological Motility 1996;8:131-41.

4 Howard PJ, Maher L, Pryde A, Heading RC. Symptomatic gastro-oesophageal reflux, abnormal oesophageal acid exposure, and mucosal acid sensitivity are three separate, though related, aspects of gastro-oesophageal reflux disease. Gut 1991;32:128-32.

5 Holloway RH, Hongo M, Berger K, McCallum RW. Gastric distention: a mechanism for postprandial gastroesophageal reflux. Gastroenterology 1985;89:779-84.

6 Wyman JB, Dent J, Heddle R, Dodds WJ, Toouli J, Downton J. Control of belching by the lower oesophageal spinc-

7 Franzi SJ, Martin CJ, Cox MR, Dent J. Response of canine lower esophageal sphincter to gastric distension. Am f Physiol 1990;259:G380-5.

8 McCallum RW, Berkowitz DM, Lerner E. Gastric emptying in patients with gastroesophageal reflux. Gastroenterology 1981;80:285-91.

9 Maddern GJ, Chatterton BE, Collins PJ, Horowitz M, Shearman DJC, Jamieson GG. Solid and liquid gastric emptying in patients with gastro-oesophageal reflux. $\mathrm{Br} \mathcal{F}$ Surg 1985;72:344-7.

10 Cunningham KM, Horowitz M, Riddel PS, et al. Relations among autonomic nerve dysfunction, oesophageal motility and gastric emptying in gastro-oesophageal reflux disease. and gastric emptying in

11 Hartley MN, Walker SJ, Mackie CR. Abnormal gastric adaptive relaxation in patients with gastro-oesophageal reflux. Gut 1990;31:500-3. 
12 Behar J, Ramsby G. Gastric emptying and antral motility in reflux esophagitis. Effect of oral metoclopramide. Gastroen reflux esophagitis. Effect
terology $1978 ; 74: 253-6$.

13 Talley NJ, Colin-Jones D, Koch KL, Koch M, Nyren O, Stanghellini V. Functional dyspepsia: a classification with guidelines for diagnosis and management. Gastroenterol Int 1991;4:145-60.

14 Klauser A, Schindlbeck N, Muller-Lissner S. Symptoms in gastro-oesophageal reflux disease. Lancet 1990;335:205-8.

15 Shi G, Bruley des Varannes S, Scarpignato C, Le Rhun M, Galmiche JP. Reflux related symptoms in patients with normal oesophageal exposure to acid. Gut 1995;37:45764.

16 Lemann M, Dederding JP, Flourie B, Franchisseur C, Rambaud JC, Jian R. Abnormal perception of visceral pain in response to gastric distension in chronic idiopathic dyspepsia. The irritable stomach syndrome. Dig Dis Sci 1991;36: 1249-54.

17 Mearin F, Cucala M, Azpiroz F, Malagelada JR. The origin of symptoms on the brain-gut axis in functional dyspepsia. of symptoms on the brain-gut axis in
Gastroenterology 1991;101:999-1006.

18 Moragas G, Azpiroz F, Pavia J, Malagelada J-R. Relations among intragastic pressure, post-cibal perception and gas-

19 Hebbard GS, Reid K, Sun WM, Horowitz M, Dent J. Postural changes in proximal gastric volume and pressure measured using a gastric barostat. Fournal of Neurogastroenterological Motility 1995;7:169-74.

20 Collins PJ, Horowitz M, Cook DJ, Harding PE, Shearman DJ. Gastric emptying in normal subjects - a reproducible technique using a single scintillation camera and computer system. Gut 1983;24:1117-25.

21 Sepple CP, Read NW. Gastrointestinal correlates of hunger in man. Appetite 1989;13:183-91.

22 Ewing DJ, Clarke BF. Diagnosis and management of diabetic autonomic neuropathy. BMf 1982;285:916-8.

23 Azpiroz F, Malagelada JR. Physiological variations in canine gastric tone measured by an electronic barostat. $\mathrm{Am} \mathcal{F}$ gastric tone measured by
Physiol $1985 ; 248: G 229-37$.

24 Ropert A, Bruley des Varannes S, Bizais Y, Roze C, Galmiche J-P. Simultaneous assessment of liquid emptying and proximal gastric tone in humans. Gastroenterology 1993;105:667-74.

25 Collins PJ, Horowitz M, Chatterton BE. Proximal, distal and total stomach emptying of a digestible solid meal in normal subjects. Br F Radiol 1988;61:12-8.

26 Azpiroz F, Malagelada J-R. Intestinal control of gastric tone. Am $\mathcal{F}$ Physiol 1985;249:G501-9.

27 Fone D, Horowitz M, Read N, Dent J, Maddox A. The effect of terminal ileal triglyceride infusion on gastroduodenal motility and the intragastric distribution of a solid meal. Gastroenterology 1990;98:568-75.

28 Janssens J, Sifrim D, Lerut A. Esophageal motility disorders: a pathophysiological concept [abstract]. Gastroenterology 1995;108:A691.
29 Azpiroz F, Malagelada J-R. Importance of vagal input in maintaining gastric tone in the dog. 7 Physiol (Lond) 1987; maintaining

30 Ogilvie AL, James PD, Atkinson M. Impairment of vagal function in reflux oesophagitis. $Q \mathcal{F} \mathrm{Med}$ 1985;213:61-74.

31 Hould F-S, Cullen JJ, Kelly KA. Influence of proximal gastric vagotomy on canine gastric motility and emptying. Surgery 1994;116:83-9.

32 Azpiroz F, Malagelada J-R. Gastric tone measured by an electronic barostat in health and postsurgical gastroparesis. Gastroenterology 1987;92:934-43.

33 Clarke RJ, Alexander-Williams J. The effect of preserving antral innervation and of a pyloroplasty on gastric

34 Gleysteen JJ, Burdeshaw JA, Hallanback GA. Gastric emptying of liquids after different vagotomies and pyloroplasty. Surg Gynecol Obstet 1976;142:41-8.

35 Holtmann G, Gschossmann J, Guerra G, Goebell H, Talley NJ. Perception of gastric distension. Influence of mode of distension on perception thresholds and gastric compliance. Dig Dis Sci 1995;40:2673-7.

36 Trimble KC, Pryde A, Heading RC. Lowered oesophageal sensory thresholds in patients with symptomatic but not excess gastro-oesophageal reflux: evidence for a spectrum of visceral sensitivity in GORD. Gut 1995;37:7-12.

37 Morley JE. Appetite regulation: the role of peptides and hormones. 7 Endocrinol Invest 1989;12:135-47.

38 Bergmann JF, Chassany O, Petit A, Triki R, Caulin C, Segrestaa JM. Correlation between echographic gastric emptying and appetite: influence of psyllium. Gut 1992;33:10423.

39 Horowitz M, Jones K, Edelbroek MA, Smout AJ, Read NW. The effect of posture on gastric emptying and intragastric distribution of oil and aqueous meal components and appetite. Gastroenterology 1993;105:382-90.

40 Mittal RK, Holloway RH, Penagini R, Blackshaw LA, Dent $\mathrm{J}$. Transient lower esophageal sphincter relaxation. Gastroenterology 1995;109:601-10.

41 Holloway RH, Kocyan P, Dent J. Provocation of transient lower esophageal sphincter relaxations by meals in patients lower esophageal sphincter relaxations by meals in patients
with symptomatic gastroesophageal reflux. Dig Dis Sci with symptomatic

42 Blackshaw LA, Grundy D, Scratcherd T. Vagal afferent discharge from gastric mechanoreceptors during contraction and relaxation of the ferret corpus. F Autonom Nerv Syst 1987;18:19-24.

43 Mittal RK, McCallum RW. Characteristics and frequency of transient relaxations of the lower esophageal sphincter on patients with reflux esophagitis. Gastroenterology 1988;95: 593-9.

44 Schoeman MN, Tippett MD, Akkermans LM, Dent J, Holloway RH. Mechanisms of gastroesophageal reflux in ambulant healthy human subjects. Gastroenterology 1995; 108:83-91. 